\title{
Dexamethasone Prevents Hypoxic-Ischemic Brain Damage in the Neonatal Rat
}

\author{
JOHN D. E. BARKS, MARTIN POST, AND URSULA I. TUOR
}

Department of Pediatrics, Division of Neonatology, The Hospital for Sick Children and The University of Toronto [J.D.E.B., M.P., U.I.T.], Department of Obstetrics and Gynecology, Toronto General Hospital [J.D.E.B.]; and The Hospital for Sick Children Research Institute [M.P., U.I.T.], Toronto, Ontario, Canada

\begin{abstract}
Glucocorticoid therapy is frequently used in perinatology and neonatology for its beneficial pulmonary effects. We investigated the influence of neonatal glucocorticoid administration on brain damage caused by a concurrent episode of cerebral hypoxia-ischemia. Various doses of dexamethasone in several treatment schedules were administered to 7-d-old rats that were also subjected to unilateral cerebral hypoxia-ischemia. In $79 \%$ of control rats, a large unilateral cerebral infarction occurred, whereas all rats pretreated with dexamethasone in doses of 0.01 to $0.5 \mathrm{mg} / \mathrm{kg} / \mathrm{d}$ for $3 \mathrm{~d}$ had no infarction $(p<$ 0.001 ). The neuroprotective effect of dexamethasone pretreatment was dose- and time-dependent. Treatment with dexamethasone after the insult or with lower doses before the insult did not prevent infarction. The neuroprotective effect was not immediate: single doses 0 to $3 \mathrm{~h}$ prehypoxia were not effective but a single dose $24 \mathrm{~h}$ before hypoxiaischemia prevented cerebral infarction. The results demonstrate that glucocorticoid administration in the neonatal period, even in low doses, protects the brain during subsequent periods of hypoxia-ischemia. (Pediatr Res 29: 558563,1991 )
\end{abstract}

Abbreviations

ANOVA, analysis of variance

At present, glucocorticoids are frequently used in perinatal medicine, both antenatally to prevent respiratory distress syndrome by inducing fetal production of pulmonary surfactant and postnatally to improve lung function in infants with bronchopulmonary dysplasia after mechanical ventilation (1-4). Both groups of infants are at risk of experiencing episodes of cerebral hypoxia-ischemia either during or after glucocorticoid administration, due to complications of prematurity and neonatal intensive care.

Glucocorticoids have long been used for the treatment of various neurologic disorders in the adult. Several beneficial effects of steroid therapy have been demonstrated. Treatment with very high doses of glucocorticoids $(3-6 \mathrm{mg} / \mathrm{kg}$ dexamethasone or $15-30 \mathrm{mg} / \mathrm{kg}$ methylprednisolone) have both reduced pathologic damage induced by experimental spinal cord trauma $(5,6)$ and improved neurologic outcome after human spinal cord injury (7). Reductions in cerebral edema caused by tumors,

Received Augusi 28, 1990; accepted January 28, 1991.

Correspondence: Dr. U. I. Tuor, Division of Neonatal Research, The Hospital for Sick Children, 555 University A venue, Toronto, Ontario, Canada M5G 1 X8. Supported by The Heart and Stroke Foundation of Ontario (Grant No. B1544), The Medical Research Council of Canada (Grant No. PG-42), The Toronto Hospital President's Fund, and Pediatric Consultants (The Hospital for Sick Children) infarction, pneumothorax, or convulsions with glucocorticoid therapy have also been reported (8-12). However, until the present study, glucocorticoid therapy did not appear to be effective in reducing brain damage due to cerebral hypoxia-ischemia. Clinical (13-15) and experimental $(16,17)$ studies indicated that, in the adult, glucocorticoids are of no benefit or are detrimental $(16,17)$ for the treatment of a focal ischemic stroke or global cerebral ischemia.

In our study, we investigated the effect of glucocorticoid administration on the extent of brain damage produced in a perinatal model of cerebral hypoxia-ischemia in the rat (18-20). The results demonstrate that in the neonate, rather than exacerbating neuronal damage, glucocorticoid administration before an episode of hypoxia-ischemia actually protects the brain from injury.

\section{MATERIALS AND METHODS}

Production of cerebral hypoxia-ischemia. Seven-d-old rats (Wistar or Sprague-Dawley) were anesthetized with halothane (4\% for induction, $0.5-1 \%$ for maintenance) and the incision site was infiltrated with $2 \%$ lidocaine. The right carotid artery was isolated and ligated. A 3-h recovery period with the dam was followed by $3 \mathrm{~h}$ in $8 \%$ oxygen with $92 \%$ nitrogen in a plastic chamber inside a neonatal incubator with an air temperature of $37^{\circ} \mathrm{C}$. This well-established model of perinatal cerebral hypoxiaischemia reliably produces ipsilateral infarction of the striatum, thalamus, hippocampus, and overlying cortex (18-20). The experimental protocol was approved by the Animal Care Committee of The Hospital for Sick Children.

Dexamethasone administration. Either dexamethasone sodium phosphate or vehicle (Sabex Inc., Montreal, Quebec, Canada) was injected intraperitoneally in several dosage schedules. Dexamethasone hemisuccinate dissolved in normal saline by warming and sonication was also used in some initial experiments. Because there was no difference in results between animals treated with dexamethasone sodium phosphate and those treated with dexamethasone hemisuccinate, the phosphate salt was used for all subsequent experiments. Animals were drawn from multiple litters for all the treatment groups and concurrent control groups.

To mimic the chronic treatment of neonates with bronchopulmonary dysplasia $(3,4)$ daily doses of dexamethasone $(0.5$ $\mathrm{mg} / \mathrm{kg} / \mathrm{d}$ ) were injected $48 \mathrm{~h}, 24 \mathrm{~h}$ and immediately before hypoxia-ischemia. In subsequent experiments, groups of animals received dexamethasone doses of $0.1,0.01,0.001$, or $0.0001 \mathrm{mg} /$ $\mathrm{kg} / \mathrm{d}$ for $3 \mathrm{~d}$. Next, the time required for dexamethasone to induce neuroprotection was investigated by administering a single dose of dexamethasone either $24 \mathrm{~h}, 3 \mathrm{~h}$, or immediately before hypoxia. In addition, the effect of dexamethasone treatment posthypoxia was tested by injecting multiple doses of either 0.5 or $1.0 \mathrm{mg} / \mathrm{kg} / \mathrm{d}$ immediately, $24 \mathrm{~h}$, and $48 \mathrm{~h}$ after the end of hypoxia. Finally, the effect of a combination of treatment both pre- and postinsult was tested with a dexamethasone dose of 0.1 
$\mathrm{mg} / \mathrm{kg}$ given at $48 \mathrm{~h}, 24 \mathrm{~h}$, and immediately before the insult and then 24 and 48 h posthypoxia.

Assessment of neuropathology. Seven d after hypoxia-ischemia, under deep anesthesia with $50 \mathrm{mg} / \mathrm{kg}$ pentobarbital or $4 \%$ halothane, brains were perfusion-fixed with $10 \%$ buffered formalin and removed. Twenty- $\mu$ m coronal sections of paraffin-embedded brains were stained with cresyl violet, hematoxylin, and eosin.

The presence or absence of gross cerebral infarction was noted on inspection of brains at the time of removal. In some animals, the extent of cerebral infarction was quantitated by measuring and comparing cross-sectional areas of brain regions ipsilateral and contralateral to the carotid ligation. Coronal sections were analyzed at 1 ) the level of the striatum anterior to the hippocampus and 2) the level of the dorsal hippocampus. A microcomputer image analysis system (MCID, Imaging Research Inc., Brock University, St. Catherine's, Ontario, Canada) was used to measure the cross-sectional area (excluding ventricles and cavitation) of the cerebral hemisphere, striatum, hippocampal formation, and neocortical mantle on the left and right sides.

Physiologic measurements. Dexamethasone administration influences many physiologic and biochemical processes. Therefore, several known systemic side effects of dexamethasone treatment (e.g. inhibition of somatic growth and hyperglycemia) were examined to determine to what degree these side effects occurred in our study.

Animals were weighed at the beginning of dexamethasone treatment, before hypoxia-ischemia, and before being killed at $14 \mathrm{~d}$ of age. Blood glucose was estimated before and after hypoxia in a subset of animals $(n=67)$ using glucose oxidase reagent strips (Chemstrip bG, Boehringer Mannheim, Germany) interpreted visually after exposure to a drop of blood obtained from the tail vessels. The heart rate before, during, and after hypoxia was measured electrocardiographically in a subset $(n=11)$ of treated $(0.1 \mathrm{mg} / \mathrm{kg} / \mathrm{d})$ and control animals. The respiratory rate before, during, and after hypoxia was measured in a different subset $(n=18)$ of treated and control animals. In addition, axillary temperature was measured in a subset of animals during hypoxia or near room temperature.

Statistical analysis. All statistical analysis were performed with a microcomputer-based program (SAS, SAS Institute Inc., Cary, NC). Fisher's exact test was used for comparisons of gross pathology and mortality. Paired or unpaired $t$ tests were used for comparisons of cross-sectional areas and heart rates. ANOVA with a Bonferroni correction for multiple comparisons was used to assess the significance of differences in weight and blood glucose.

\section{RESULTS}

Pretreatment with a high dexamethasone dose. Dexamethasone pretreatment at $0.5 \mathrm{mg} / \mathrm{kg} / \mathrm{d}$ for $3 \mathrm{~d}$ prevented brain damage associated with $3 \mathrm{~h}$ of cerebral hypoxia-ischemia in the neonatal rat. Cerebral infarction with gliosis or liquefaction ipsilateral to the carotid ligation occurred in the majority ( 31 of 39 , or $79 \%$ ) of control animals, but was absent in all dexamethasone-pretreated animals $(p<0.001$; Fig. 1). In control animals, there were marked reductions in the cross-sectional areas of cortex $(56 \%)$, dorsal hippocampus $(61 \%)$, striatum $(41 \%)$, and hemisphere (40-48\%) ipsilateral to the carotid ligation $(p<0.001)$, whereas the two sides were indistinguishable in dexamethasonepretreated animals (Table 1; Fig. 2).

Pretreatment with lower dexamethasone doses. Dexamethasone pretreatment was observed to prevent brain damage over a wide dose range (Fig. 3). Cerebral infarction did not occur in animals receiving a dose as low as $0.01 \mathrm{mg} / \mathrm{kg} / \mathrm{d}(p<0.001)$. Below this dose, the incidence of gross infarction did not differ from that of controls. The incidence of mortality during and after hypoxia did not differ between the control and dexamethasone-treated groups (Fig. 3).

Pretreatment with a single dexamethasone dose. Hypoxicischemic brain damage could also be prevented with a single

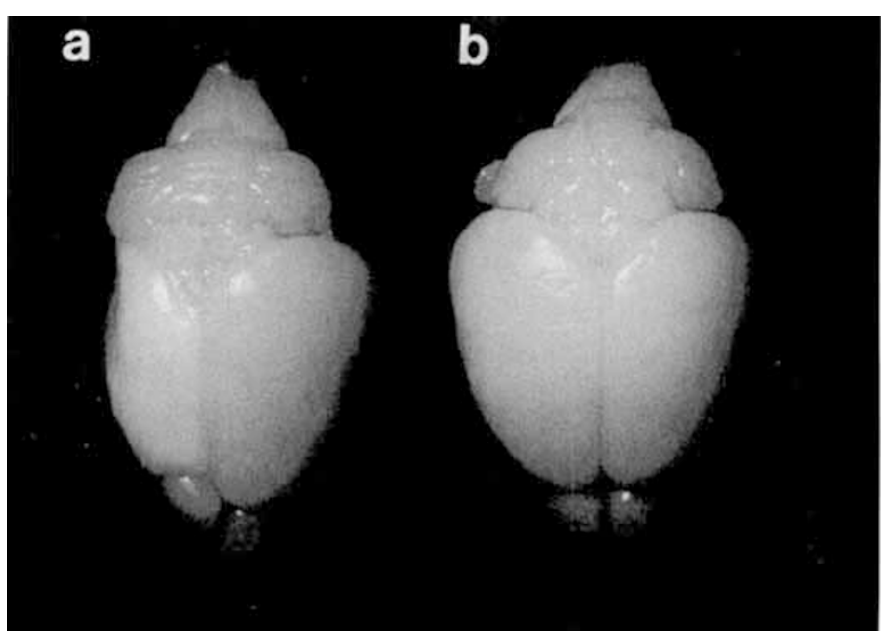

Fig. 1. View of brains of neonatal rats subjected to unilateral cerebral hypoxia-ischemia at $7 \mathrm{~d}$ of age. The rats were pretreated with either vehicle or dexamethasone $(0.5 \mathrm{mg} / \mathrm{kg} / \mathrm{d}$ for $3 \mathrm{~d})$. Brains were perfusion fixed $7 \mathrm{~d}$ posthypoxia. Note the pallor and contraction of the right hemisphere of the vehicle-treated animal $(a)$, which is not seen in the dexamethasone-pretreated animal (b).

Table 1. Morphometric analysis of the effect of dexamethasone treatment on hypoxic-ischemic brain injury

\begin{tabular}{|c|c|c|c|c|}
\hline & \multicolumn{4}{|c|}{ Cross-sectional area $\left(\mathrm{mm}^{2}\right)^{*}$} \\
\hline & \multicolumn{2}{|c|}{ Vehicle } & \multicolumn{2}{|c|}{ Dexamethasone $\dagger$} \\
\hline & Right & Left & Right & Left \\
\hline Pretreatment & \multicolumn{2}{|c|}{$(n=13)$} & \multicolumn{2}{|c|}{$(n=16)$} \\
\hline Cortex & $4.0 \pm 0.7 \S$ & $9.1 \pm 0.7$ & $9.9 \pm 0.4$ & $9.7 \pm 0.4$ \\
\hline $\begin{array}{l}\text { Hippo- } \\
\text { campus }\end{array}$ & $1.2 \pm 0.3 \S$ & $3.1 \pm 0.3$ & $2.9 \pm 0.8$ & $3.1 \pm 0.2$ \\
\hline Striatum & $2.9 \pm 0.5 \S$ & $4.9 \pm 0.5$ & $4.9 \pm 0.2$ & $4.7 \pm 0.2$ \\
\hline $\begin{array}{l}\text { Hemi- } \\
\text { sphere\|l }\end{array}$ & $15.1 \pm 1.7 \S$ & $25.0 \pm 1.8$ & $24.6 \pm 0.8$ & $24.1 \pm 0.7$ \\
\hline Posttreatment & \multicolumn{2}{|c|}{$(n=6)$} & \multicolumn{2}{|c|}{$(n=6)$} \\
\hline Cortex & $5.9 \pm 0.9 \S$ & $11.5 \pm 0.8$ & $4.6 \pm 1.4^{* *}$ & $9.8 \pm 0.9$ \\
\hline $\begin{array}{l}\text { Hippo- } \\
\text { campus }\end{array}$ & $1.3 \pm 0.3 \S$ & $3.9 \pm 0.6$ & $1.4 \pm 0.5^{* *}$ & $2.7 \pm 0.3$ \\
\hline Striatum & $2.9 \pm 0.5 \S$ & $6.5 \pm 0.6$ & $2.9 \pm 0.5^{* *}$ & $4.8 \pm 0.5$ \\
\hline Hemi- & $17.4 \pm 1.7 \S$ & $30.2 \pm 1.6$ & $12.9 \pm 1.8^{* *}$ & $23.4 \pm 2.2$ \\
\hline
\end{tabular}

spherell

* Data presented as mean $\pm \mathrm{SEM}$.

$\uparrow 0.5 \mathrm{mg} / \mathrm{kg} / \mathrm{d}$ for $3 \mathrm{~d}$.

$\ddagger p<0.001$; paired $t$ test of percent right-left difference between vehicle and dexamethasone pretreatment.

$\S p<0.001$; paired $t$ test of percent differences between right side (carotid artery occluded) and left side.

$\|$ Area of the hemisphere at the level of the striatum anterior to the hippocampus.

I $p=\mathrm{NS}$; paired $t$ test of percent right-left difference between vehicle and dexamethasone posttreatment.

${ }^{* *} p<0.05$; paired $t$ test of percent differences between right side (carotid artery occluded) and left side.

dose of dexamethasone, but this effect was dependent on the time interval between injection and hypoxia-ischemia. Dexamethasone $(0.1 \mathrm{mg} / \mathrm{kg})$ injected $24 \mathrm{~h}$ before the insult prevented cerebral infarction, but dexamethasone administered either immediately or $3 \mathrm{~h}$ before the insult had no such effect $(p<0.001$, Fig. 4). There was no difference in mortality during and after hypoxia between the control and single-dose treatment groups (Fig. 4).

Effect of dexamethasone treatment posthypoxia. In contrast to the marked neuroprotective effect of pretreatment, dexametha- 

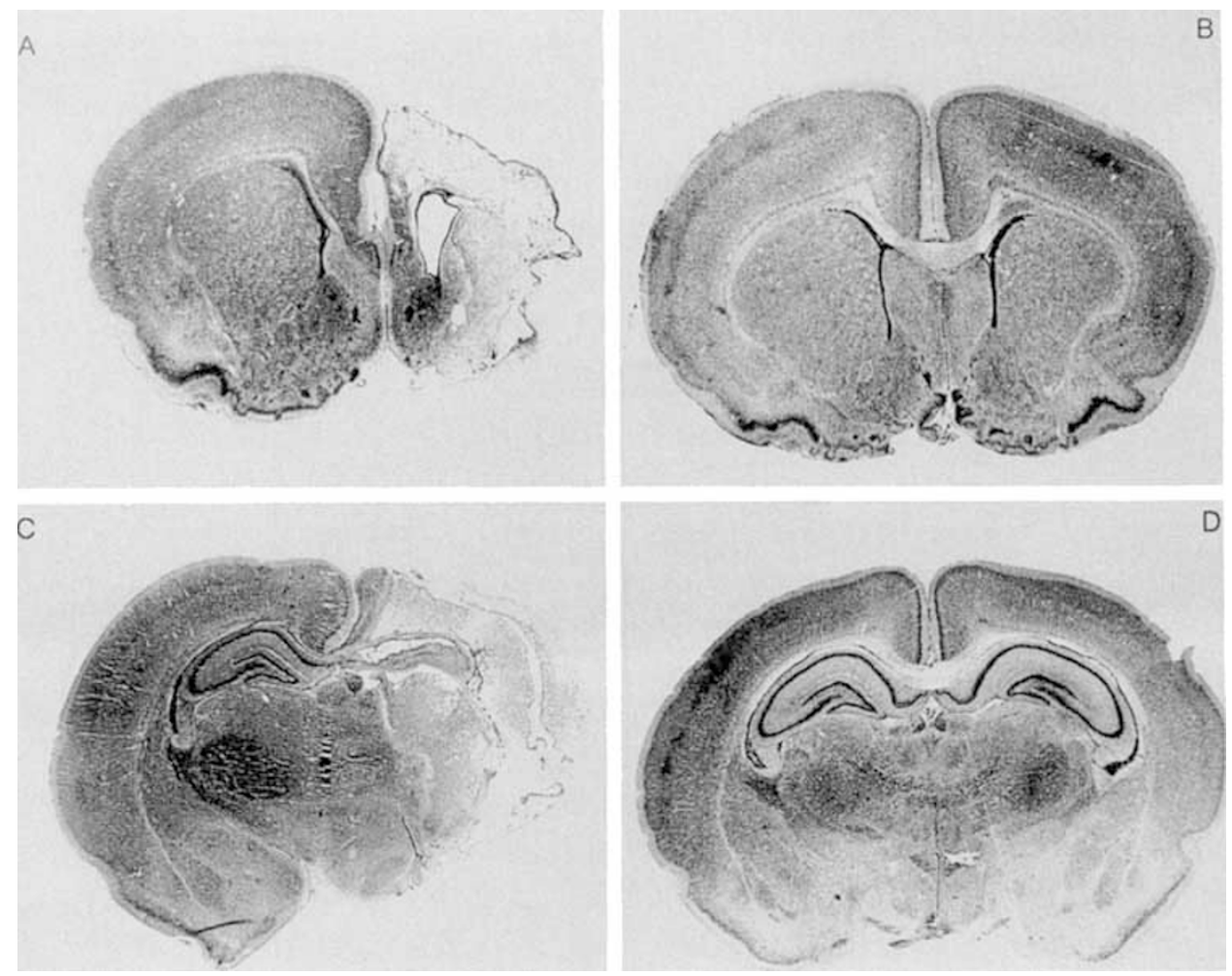

Fig. 2. Light photomicrographs of brain sections of 2-wk-old rats that demonstrate the cerebral protective effect of dexamethasone. Animals were pretreated with dexamethasone $(0.5 \mathrm{mg} / \mathrm{kg} / \mathrm{d}$ for $3 \mathrm{~d})$ and subjected to a period of cerebral hypoxia-ischemia at $7 \mathrm{~d}$ of age. Histologic sections are at the level of the striatum in animals treated with vehicle $(A)$ and dexamethasone $(B)$ and at the level of the dorsal hippocampus in animals treated with vehicle $(C)$ and dexamethasone $(D)$.

sone treatment posthypoxia did not prevent brain injury. Gross unilateral cerebral infarction occurred in the majority of control and dexamethasone posttreated animals (Fig. 5). Similarly, the reduction in cross-sectional areas ipsilateral to carotid ligation did not differ significantly between the dexamethasone posttreatment and control groups (Table 1). In contrast, a combination of pre- and posthypoxia dexamethasone treatment was neuroprotective (Fig. 5).

Physiologic effects of dexamethasone treatment. The administration of glucocorticoids at doses that were neuroprotective also produced a decrease in somatic growth. At the time of hypoxia, animals pretreated with dexamethasone $(0.001$ to $0.5 \mathrm{mg} / \mathrm{kg} / \mathrm{d}$ for $3 \mathrm{~d}$ or $0.1 \mathrm{mg} / \mathrm{kg}$ for $24 \mathrm{~h}$ before hypoxia) weighed approximately $20 \%$ less than controls $(p<0.05$, ANOVA with Bonferroni correction, Fig. 6). However, by $7 \mathrm{~d}$ after hypoxia, only animals treated with dexamethasone posthypoxia still weighed significantly less than controls $(50-58 \%$ of mean control weight of $25.2 \pm 0.7 \mathrm{~g}, p<0.05$, ANOVA).

Dexamethasone pretreatment also influenced systemic glucose metabolism during hypoxia. Before hypoxia, there was no significant difference in blood glucose between control animals and all dexamethasone-treated groups $(p>0.05$, ANOVA, mean control blood glucose, $5.4 \pm 0.3 \mathrm{mmol} / \mathrm{L})$. However, after hypoxia, animals in most dexamethasone treatment groups were hyperglycemic compared to controls. Furthermore, an inverse relationship between posthypoxia blood glucose and incidence of cerebral infarction was observed (Figs. 3 and 4).

No marked effect of dexamethasone on the cardiorespiratory function of neonatal rats could be demonstrated. Cardiac monitoring during hypoxia demonstrated that, although initial heart rates tended to be slightly less in dexamethasone-treated animals $(0.1 \mathrm{mg} / \mathrm{kg} / \mathrm{d})$, these differences were not statistically significant (Fig. 7). Furthermore, the heart rate changes during hypoxia were similar in dexamethasone-treated and control subjects (Fig. 7).

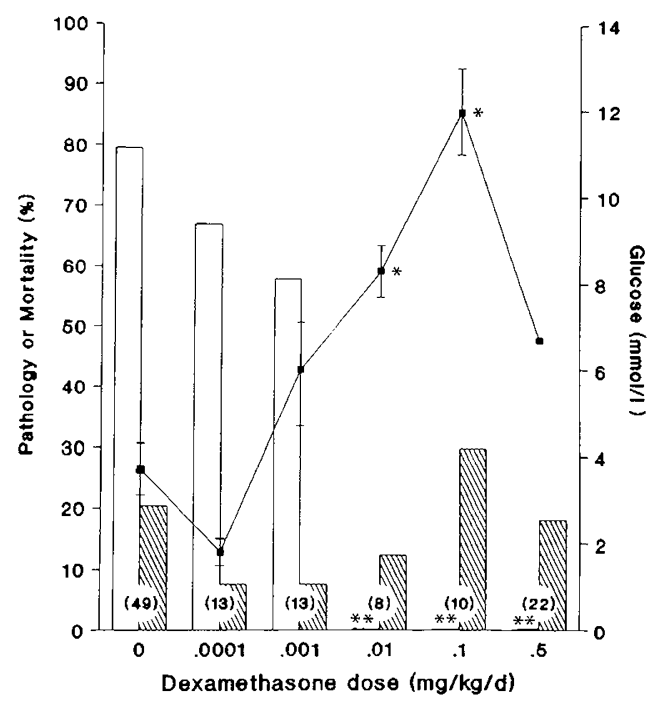

Fig. 3. The effect of multiple doses of dexamethasone administered prehypoxia on pathology, mortality, and blood glucose. The incidence of gross cerebral infarction, which is presented as a percentage of survivors in each group (open bars), was dependent on the dose of dexamethasone injected daily $(48,24$, and $0 \mathrm{~h}$ before hypoxia-ischemia). The mortality that occurred during and after hypoxia was similar in all groups (hatched bars, \% of total $n$ in parentheses). The levels of blood glucose measured immediately posthypoxia were elevated at the higher doses of dexamethasone treatment (closed squares, mean $\pm \mathrm{SEM}) . *, p<0.05 ; * *, p<$ 0.001 , different from vehicle $(0 \mathrm{mg} / \mathrm{kg} / \mathrm{d})$. 


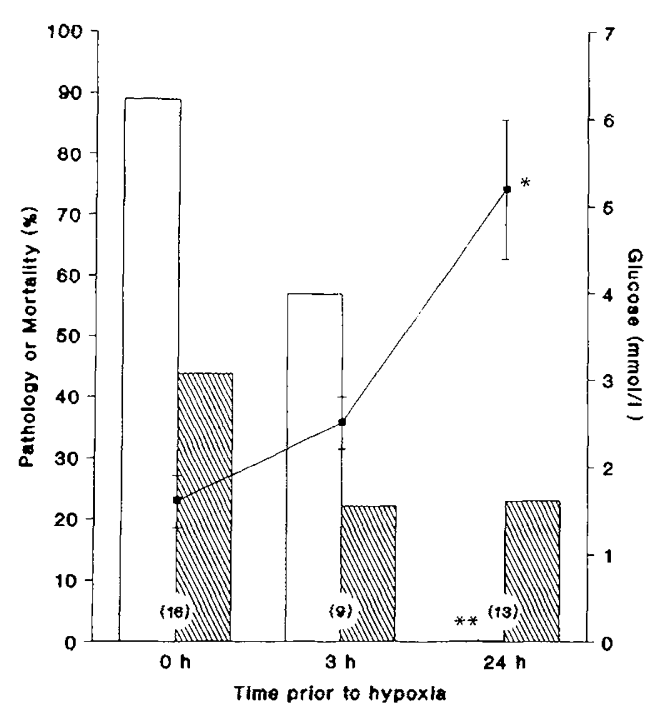

Fig. 4. The effect on pathology, mortality, and blood glucose of a single dose of dexamethasone administered at different times before the onset of hypoxia-ischemia (doses: $0.5,0.1$, and $0.1 \mathrm{mg} / \mathrm{kg}$ at 0,3 , or 24 h prehypoxia, respectively). The incidence of gross cerebral infarction (\% survivors, open bars) was reduced in the group injected $24 \mathrm{~h}$ before hypoxia-ischemia. Mortality ( $\%$ of total $n$ in parentheses, hatched bars) was similar in all groups. Blood glucose levels at the end of hypoxia were elevated in the group injected $24 \mathrm{~h}$ before hypoxia-ischemia (closed squares, mean $\pm \mathrm{SEM}) .{ }^{*}, p<0.05 ; * *, p<0.001$, different from groups injected 0 and $3 \mathrm{~h}$ prehypoxia.

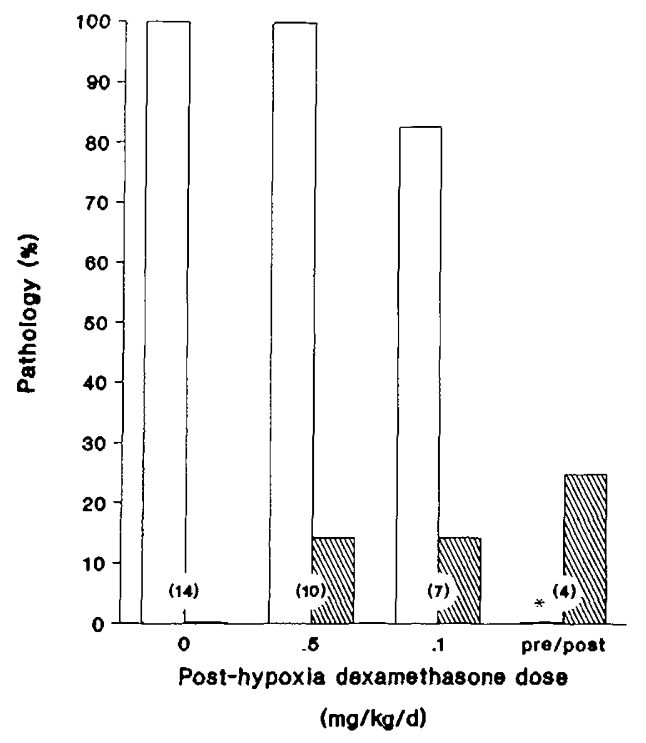

Fig. 5. The effect on pathology and mortality of dexamethasone treatment posthypoxia-ischemia. The incidence of gross pathology (\% survivors, open bars) was similar in animals posttreated with daily injections of vehicle or dexamethasone $(0,24$, and $48 \mathrm{~h}$ after hypoxiaischemia). In contrast, gross cerebral infarction was prevented by dexamethasone treatment both pre- and posthypoxia-ischemia $(0.1 \mathrm{mg} / \mathrm{kg}$ : $-48,-24,0,+24$, and $+48 \mathrm{~h}$ from the start of hypoxia-ischemia). Mortality (\% total $n$ in brackets, hatched bars) was similar in all groups. ${ }^{*}, p<0.05$, different compared to vehicle $(0 \mathrm{mg} / \mathrm{kg} / \mathrm{d})$.

Respiratory rates, which varied from 80 to 180 breaths/min during hypoxia, were similar in dexamethasone-treated and control animals.

Axillary temperature during hypoxia-ischemia was similar in dexamethasone- and vehicle-treated animals. Within the hypoxia chamber (ambient temperature $\sim 37^{\circ} \mathrm{C}$ ), axillary temperature was $39.2 \pm 0.2^{\circ} \mathrm{C}$ in 13 dexamethasone-treated $(0.1 \mathrm{mg} / \mathrm{kg}, 24 \mathrm{~h}$ prehypoxia) and $39.2 \pm 0.2^{\circ} \mathrm{C}$ in 12 vehicle-treated rats. Axillary

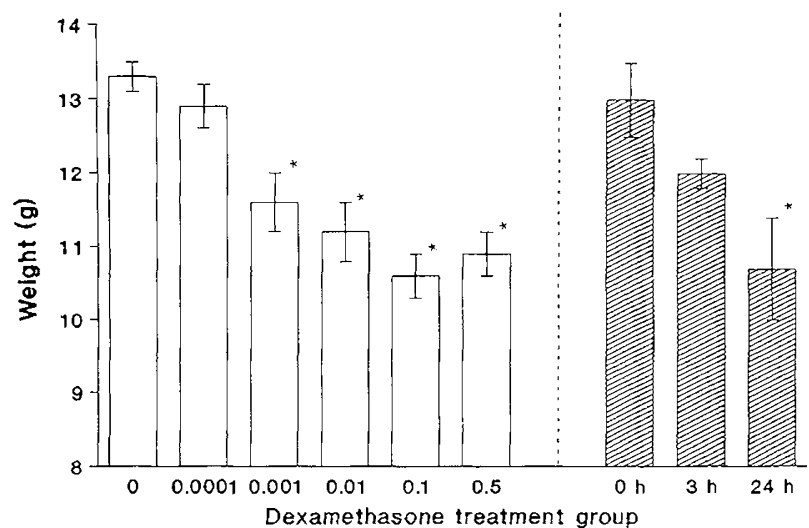

Fig. 6. Reduction in somatic growth with dexamethasone pretreatment. Body weight at $7 \mathrm{~d}$ was reduced in animals receiving repeated daily doses of vehicle or dexamethasone (open bars) or a single dose of dexamethasone (hatched bars) at 0,3 , or $24 \mathrm{~h}$ prehypoxia (doses of 0.5 , 0.1 , or $0.01 \mathrm{mg} / \mathrm{kg}$, respectively). ${ }^{*}, p<0.05$, different from vehicle $(0 \mathrm{mg} / \mathrm{kg} / \mathrm{d})$.

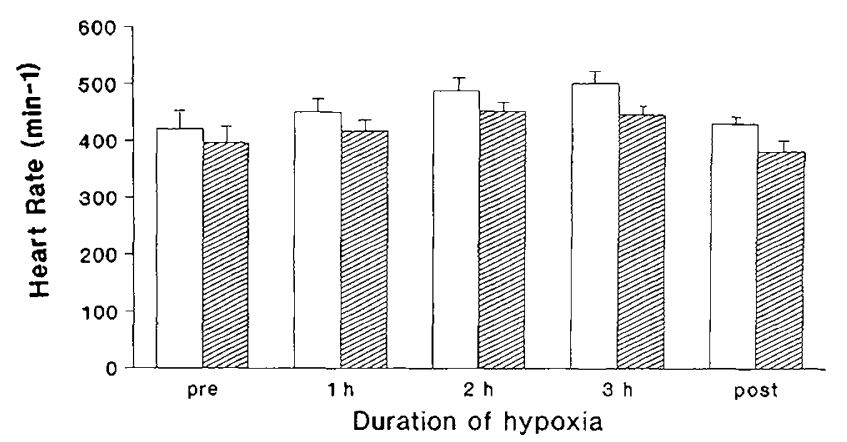

Fig. 7. Effect of dexamethasone pretreatment on heart rate during hypoxia. Heart rate (mean \pm SEM) was similar in dexamethasonepretreated $(0.1 \mathrm{mg} / \mathrm{kg} / \mathrm{d}$ ) (hatched bars) and control animals (open bars) at all times points.

temperature measured at an ambient temperature of $\sim 27^{\circ} \mathrm{C}$ was $34.7 \pm 0.2$ and $35.1 \pm 0.2^{\circ} \mathrm{C}$ in dexamethasone- $(n=9)$ and vehicle $(n=7)$-treated animals, respectively.

\section{DISCUSSION}

Our results demonstrate that, in the neonatal period, treatment with dexamethasone before an episode of cerebral hypoxiaischemia provides a marked protection against brain damage. This dramatic effect of glucocorticoid treatment in the neonate was surprising in view of concerns about the negative effects of perinatal glucocorticoid therapy on the developing nervous system $(21,22)$ and the previous lack of success of glucocorticoids for the pre- or posttreatment of focal or global ischemia in the adult (13-17). Furthermore, in neonatal rats, Altman et al. (23) demonstrated that a single very large dose of dexamethasone (4 or $40 \mathrm{mg} / \mathrm{kg}$ ) immediately before unilateral cerebral hypoxiaischemia was actually harmful in that it increased mortality. Indeed, based on such discouraging results from studies in the adult and neonate, glucocorticoid therapy was recently not recommended for the treatment of newborn infants with hypoxicischemic encephalopathy (24). In agreement with several of these previous studies, our results demonstrate that posttreatment or immediate pretreatment with dexamethasone is ineffective in improving the pathology caused by an episode of perinatal cerebral hypoxia-ischemia. In contrast to findings in the adult, pretreatment with dexamethasone prevents hypoxic-ischemic brain damage in the neonate.

Our study also demonstrates several other unique aspects of glucocorticoid treatment. The neuroprotective effect of dexamethasone occurs not only at high doses, but also at doses much 
lower (e.g. $0.01 \mathrm{mg} / \mathrm{kg} / \mathrm{d}$ ) than those commonly used in glucocorticoid therapy for CNS trauma, edema, or hypoxia/ischemia $(6,9,13,15)$. In addition, the results demonstrate that pretreatment with dexamethasone is ineffective if it is administered either immediately or $3 \mathrm{~h}$ before the hypoxic-ischemic incident, indicating that there is a latency of action of the relevant dexamethasone-induced effect of several hours.

The actual mechanism by which dexamethasone prevents neonatal hypoxic-ischemic brain damage cannot be determined from our data. However, of the many documented effects of dexamethasone treatment that have the potential to modify hypoxic-ischemic damage, several are unlikely to be involved in the neuroprotective action observed presently. Dexamethasone at very high doses has been reported to exert a stabilizing effect directly on the cell membrane (25). The latency of action of dexamethasone in the present study and its effectiveness at very low doses suggest that dexamethasone is not acting via a direct membrane effect but rather by inducing a biochemical or physiologic alteration at the cellular level that requires more than 3 $\mathrm{h}$ to become functional. Hypertension and bradycardia have been reported to occur in neonates that are treated with dexamethasone for bronchopulmonary dysplasia $(26,27)$. In the rats, there was no major difference in heart rate between glucocorticoid- or vehicle-treated animals, suggesting that dexamethasone is not preventing neonatal brain damage by a systemic circulatory effect. This is supported by preliminary results from studies in which we have measured cerebral blood flow after $3 \mathrm{~h}$ of hypoxia using autoradiographic techniques adapted for the 7-d-old rat (28). The data show that, in regions that are damaged in this model of hypoxia-ischemia (e.g. cerebral cortex, striatum and hippocampus), cerebral blood flow is reduced by $50-60 \%$ ipsilaterally in both dexamethasone- and vehicle-treated animals (unpublished experiments).

Additional available evidence indicates that other effects of glucocorticoid therapy can modify cerebral hypoxic-ischemic damage. For example, growth retardation, which occurred in dexamethasone-treated animals, has been shown by Trescher et al. (29) to protect the developing nervous system from hypoxicischemic injury. Similarly, hyperglycemia, which exacerbates ischemic damage in the adult, has been shown to reduce or not alter hypoxic-ischemic injury in the immature brain (30-33). Although these effects may contribute to the response, neither hyperglycemia nor growth retardation alone were observed to confer as complete a cerebral protection as occurred with dexamethasone administration in our present study. Certainly, the fact that hyperglycemia and dexamethasone both influence hypoxic-ischemic brain damage differently in the immature compared to the adult animal suggests that the role of glucocorticoidinduced hyperglycemia should be investigated further. However, there are many differences between the neonate and the adult that could contribute to the differential age dependence of the glucocorticoid effects. Developmental changes in the hypothalamic-pituitary axis and glucocorticoid receptors occur in the first 2 wk of life (34), whereas within the brain there are marked increases in blood flow and cerebral glucose metabolism postnatally that may also alter glucocorticoid effects (35-37). Clearly, additional experiments are required to determine the mechanisms by which dexamethasone is affecting the response to hypoxia-ischemia.

Irrespective of the mechanisms involved, our study indicates that pretreatment with glucocorticoids at doses analogous to or less than those used to treat bronchopulmonary dysplasia protects the brain from damage due to perinatal hypoxia-ischemia. These data provide a further rationale for prenatal glucocorticoid administration to the fetus at risk of premature delivery and its complications, which include hypoxic-ischemic brain damage. Neurodevelopmental follow-up data from one controlled trial of dexamethasone for bronchopulmonary dysplasia indicate an improved outcome in steroid-treated infants (4), but neurosonography in another controlled trial of dexamethasone for broncho- pulmonary dysplasia showed an increased incidence of periventricular leukomalacia in dexamethasone-treated infants (38). In view of increasing postnatal use of glucocorticoids in infants with bronchopulmonary dysplasia, our findings indicate that attention should be focused on the potential neuroprotective effects for neonates entered in controlled trials of glucocorticoids, who may continue to be at risk for hypoxic-ischemic brain injury due to the severity of their lung disease and other complications of neonatal intensive care.

Acknowledgments. The authors thank Saro Bascaramurty and Jaromir Bertlik for their excellent technical assistance.

\section{REFERENCES}

1. Collaborative Group on Antenatal Steroid Therapy 1985 Prevention of Respiratory Distress Syndrome: Effect of Antenatal Dexamethasone Administration. US Department of Health And Human Services, NIH Publication 85-2695, Washington, DC

2. Post M, VanGolde LMG 1988 Metabolic and developmental aspects of the pulmonary surfactant system. Biochim Biophys Acta 947:249-286

3. Avery GB, Fletcher AB, Kaplan M, Brudno DS 1985 Controlled trial of dexamethasone in respirator-dependent infants with bronchopulmonary dysplasia. Pediatrics 75:106-111

4. Cummings JJ, D'Eugenio DB, Gross SJ 1989 A controlled trial of dexamethasone in premature infants at high risk for bronchopulmonary dysplasia. $N$ Engl J Med 320:1505-1510

5. Young W, Flamm ES 1982 Effect of high-dose corticosteroid therapy on blood flow, evoked potentials, and extracellular calcium in experimental spinal injury. J Neurosurg 57:667-673

6. Braughler JM, Hall ED 1985 Current application of high dose steroid therapy for CNS trauma. J Neurosurg 62:806-810

7. Bracken MB, Shephard MJ, Collins WF, Holford TR, Young W, Baskin DS, Eisenberg HM, Flamm E, Leo-Summers L, Maroon J, Marshall LF, Perot PL, Piepmeier J, Sonntag VKH, Wagner FC, Wilberger JE, Winn HR 1990 A randomized controlled trial of methylprednisolone or naloxone in the treatment of acute spinal cord injury. N Engl J Med 322:1405-1411

8. Nakagawa H, Groothuis DR, Owens ES, Fenstermacher JD, Patlak CS, Blasberg RG 1987 Dexamethasone effects on [ ${ }^{125}$ I] albumin distribution in experimental RG-2 gliomas and adjacent brain. J Cereb Blood Flow Metab 7:687-701

9. Barbosa-Coutinho LM, Hartmann A, Hossmann KA, Rommel T 1985 Effect of dexamethasone on serum protein extravasation in experimental brain infarcts of monkcy: an immunohistochemical study. Acta Neuropathol (Berl) 65:255-260

10. Fenske A, Fischer M, Regli F, Hase U 1979 The response of focal ischemic cerebral edema to dexamethasone. J Neurol 220:199-209

11. Temesvari P, Joo F, Koltai M, Eck E, Adam G, Siklos L, Boda D 1984 Cerebroprotective effect of dexamethasone by increasing the tolerance to hypoxia and preventing brain oedema in newborn piglets with experimental pneumothorax. Neurosci Lett 49:87-92

12. Sztriha L, Joo F, Szerdahelyi P, Eck E, Koltai M 1986 Effects of dexamethasone on brain edema induced by kainic acid seizures. Neuroscience 17:107-114

13. Norris JW, Hachinski VC 1986 High dose steroid treatment in cerebral infarction. Br Med (Clin Res) 292:21-23

14. Goldstein M, Barnett HJM, Orgogozo JM, Sartorius N, Symon L, Vereschagin NV 1989 Recommendations on stroke prevention, diagnosis and therapy: report of the WHO task force on stroke and other cerebrovascular disorders. Stroke 20:1407-1431

15. Jastremski M, Sutton-Tyrell K, Vaagenes P, Abramson N, Heiselman D, Safar $\mathrm{P}$ (The Brain Resuscitation Clinical Trial I Study Group) 1989 Glucocorticoid treatment does not improve neurologic recovery following cardiac arrest. JAMA 262:3427-3430

16. Sapolsky RM, Pulsinelli WA 1985 Glucocorticoids potentiate ischemic injury to neurons: therapeutic implications. Science 229:1397-1400

17. Koide T, Wieloch TW, Siesjo BK 1986 Chronic dexamethasone pretreatment aggravates ischemic neuronal necrosis. J Cereb Blood Flow Metab 6:395404

18. Silverstein F, Torke L, Barks J, Johnston MV 1987 Hypoxia-ischemia produces focal disruption of glutamate receptors in developing brain. Dev Brain Res 34:33-39

19. Rice JE, Vannucci RC, Brierly JB 1983 The influence of immaturity on hypoxic-ischemic brain injury in the rat. Ann Neurol 9:131-14I

20. Dwyer BE, Nishimura RN, Fujikawa DG 1988 Cerebral hypoxia-ischemia in immature rats: methodological considerations. Exp Neurol 99:772-777

21. Weichsel ME 1977 The therapeutic use of glucocorticoid hormones in the perinatal period: potential neurologic hazards. Ann Neurol 2:364-366

22. Uno H, Lohmiller L, Thieme C, Kemnitz JW, Engle MJ, Roecker EB, Farrell PM 1990 Brain damage induced by prenatal exposure to dexamethasone in fetal rhesus macaques. I. Hippocampus. Dev Brain Res 53:157-167

23. Altman DI, Young RSK, Yagel SK 1984 Effects of dexamethasone in hypoxicischemic brain injury in the neonatal rat. Biol Neonate 46:149-156

24. Vannucci RC 1990 Current and potentially new management strategies for perinatal hypoxic-ischemic encephalopathy. Pediatrics 85:961-968 
25. Hall ED, Braughler JM 1982 Glucocorticoid mechanisms in acute spinal cord injury: a review and therapeutic rationale. Surg Neurol 18:320-327

26. Ohlsson A. Heyman E 1988 Dexamethasone-induced bradycardia. Lancet $2: 1074$

27. Puntis JWI, Morgan MEI, Durbin GM 1988 Dexamethasone-induced bradycardia. Lancet 2:1372

28. Lyons DT. Vasta F, Vannucci RC 1987 Autoradiographic determination of regional cerebral blood flow in the immature rat. Pediatr Res 21:471-476

29. Trescher WH, Lchman RA, Vannucci RC 1990 The influence of growth retardation on perinatal hypoxic-ischemic brain damage. Early Hum Dev $21: 165-173$

30. Thurston JH, Hauhart RE, Dirgo JA, Jones EM 1980 Mechanisms of increased brain glucose and glycogen after hydrocortisone: possible clinical significance. Ann Neurol 7:515-523

31. Callahan DJ, Engle MJ, Volpe JJ 1980 Hypoxic injury to developing glial cells: protective effect of high glucose. Pediatr Res 27:186-190

32. Hattori H, Wasterlain CG 1990 Posthypoxic glucose supplement reduces hypoxic-ischemic brain damage in the neonatal rat. Ann Neurol 28:122-128
33. Voorhies TM, Rawlinson D, Vannucci RC 1986 Glucose and perinatal hypoxic-ischemic brain damage in the rat. Neurology 36:1115-1118

34. De Kloet ER, Rosenfeld P. Van Eekclen AM, Sutanto W, Levine S 1988 Stress, glucocorticoids and development. In: Boer GI, Feenstra GP. Mirmiran M, Swaab, Van Haaren F (eds) Progress in Brain Research, Vol 73. Elsevier Science, pp 101-119

35. Tuor UI 1991 Local cerebral blood flow in the newborn rabbit: an autoradiographic study of changes during development. Pediatr Res 29:517-523

36. Vannucci RC, Christensen MA, Stein DT 1989 Regional cerebral glucose utilization in the immature rat: effect of hypoxia-ischemia. Pediatr Res 26:208-214

37. Nehlig A, de Vasconcelos AP. Boyet S 1988 Quantitative autoradiographic measurement of local cerebral glucose utilization in freely moving rats during postnatal development. J Neurosci 8:2321-2333

38. Noble-Jamieson CM, Regev R, Silverman M 1989 Dexamethasone in neonatal chronic lung disease: pulmonary cffects and intracranial complications. Eur J Pediatr 148:365-367

\section{Announcements}

\section{First World Congress of Cellular and Molecular Biology}

The First World Congress of Cellular and Molecular Biology will be held September 1-7, 1991 in Paris and Versailles, Palais des Congrès. It is organized by the editors of the journal Cellular and Molecular Biology, together with several outstanding personalities in the scientific world, and will include about 40 symposia on the most promising themes in the field.

For further information, contact: Mrs. Leila Orbecchi, Director, C.E.R.T., 63, Avenue Parmentier, 75011 Paris, France. Phone: 33 (1) 480707 00; FAX: 33 (1) 48072211.

\section{Scientific Meeting}

The Society for Behavioral Pediatrics will conduct its 9th Annual Scientific Meeting and Workshops on September 21-23, 1991 at the Omni Inner Harbor Hotel in Baltimore, MD. For further information and registration forms, please contact Ms. Noreen Spota at (215) 248-9168. 